\title{
ANALISIS DAN PERBAIKAN LAYANAN HOTEL MENGGUNAKAN SERVQUAL DAN DIAGRAM KARTESIUS (Studi Kasus di Hotel Kombokarno)
}

\author{
Rindang Rayo Ranas \\ Magister Teknik Industri Universitas Islam Indonesia \\ rindangrr@yahoo.co.id \\ Agus Mansur \\ Fakultas Teknik Industri Universitas Islam Indonesia \\ qus_mansur@uii.ac.id
}

\begin{abstract}
The purposes of this research is to analyze and suggest a service quality improvement in Kombokarno Hotel. This research used ServQual dimension variables that consist of tangible, reliability, responsiveness, assurance, and empathy as a dimensions of service quality. It used 144 guests of Kombokarno Hotel as a sample for the research. The result of the collected data then be tested based on it's validation and reliability by using SPSS 16.0 software. The result of data processing shows the validity of each question variable in the questionnaire. Then the data be analyzed using ServQual method to see the Gap between hope and reality. Furthermore it is processed by Kartesius diagram to see what performance that need to be improved. The result of the researched shows that the cleanness of the hotel always in good term, the electronic utilities (lamp, AC, $T V$, etc), are functioned well, and the hotel's building 'good look' became the most priority to improve the performance of service quality in the hotel.
\end{abstract}

Keyword: ServQual, diagram kartesius, service quality

\section{PENDAHULUAN}

Industri perhotelan merupakan salah satu aspek yang harus diperhitungkan di kota Yogyakarta sebagai kota pariwisata. Menurut BPS (Biro Pusat Statistik), jumlah hotel bintang dan non-bintang di Yogyakarta pada tahun 2009 sebanyak 1125 sedangkan pada tahun 2010 meningkat menjadi 1181. Hal ini menunjukkan tingginya persaingan di dalam industri hotel di Yogyakarta. Dengan tingginya persaingan, para pengelola/manajer hotel perlu meningkatkan kualitas layanan hotel agar memiliki competitive advantage. 
Tantangan yang dihadapi dalam memberikan layanan di hotel saat ini, seperti tingginya permintaan konsumen terhadap kualitas, secara langsung berkaitan untuk lebih memahami atribut pelayanan hotel serta untuk meningkatkan desain layanan yang sesuai dengan karakteristik hotel tersebut. Desain merupakan salah satu aspek yang dapat dijadikan faktor utama untuk mendapatkan competitive advantage.

Menurut İkiz \& Masoudi (2008), kebanyakan pengelola/manajer hotel hanya melihat desain dari beberapa aspek layanan hotel, seperti desain interior atau layanan berbasis internet. Hanya sedikit usaha yang dilakukan para pengelola untuk mendapatkan feed back dari para pelanggan. Namun menurut mereka (İkiz \& Masoudi), masih terdapat kekurangan apabila hanya menggunakan feed back dari pelanggan sebagai dasar untuk memprioritaskan desain layanan. Beberapa rangkuman penelitian terdahulu yang telah dilakukan mengenai kualitas layanan hotel disajikan dalam Tabel 1.

Tabel 1. Ringkasan Penelitian Terdahulu

\begin{tabular}{lll}
\hline \multicolumn{1}{c}{ Peneliti } & \multicolumn{1}{c}{ Metode } & \multicolumn{1}{c}{ Hasil penelitian } \\
\hline $\begin{array}{l}\text { Kay C. Tan dan } \\
\text { Theresia A. Pawitra } \\
\text { (2001) }\end{array}$ & $\begin{array}{l}\text { Servqual, model } \\
\text { Kano, dan QFD }\end{array}$ & $\begin{array}{l}\text { Membantu pengelola hotel dalam mengevaluasi } \\
\text { kepuasan pelanggan/konsumen }\end{array}$ \\
$\begin{array}{l}\text { Dr. sc. Jasmina } \\
\text { Gržinić (2007) }\end{array}$ & Servqual & $\begin{array}{l}\text { Mengetahui terdapat ketidaktahuan manager hotel } \\
\text { mengenai harapan layanan yang diinginkan oleh } \\
\text { para konsumen. }\end{array}$ \\
$\begin{array}{l}\text { Aysun Kapucugil İkiz } \\
\text { \& Ali Masoudi (2008) }\end{array}$ & Servqual dan & $\begin{array}{l}\text { Menilai kinerja layanan suatu hotel dengan } \\
\text { memodifikasi QFD, yaitu dengan menggunakan } \\
\text { dimensi Servqual dalam Costomer Requirement. }\end{array}$ \\
$\begin{array}{l}\text { Suzana Markovi'c } \\
\text { dan Sanja Raspor } \\
\text { (2010) }\end{array}$ & Servqual & $\begin{array}{l}\text { Aspek-aspek yang diinginkan oleh konsumen dalam } \\
\text { pelayanan adalah memecahkan masalah yang } \\
\text { dihadapi oleh tamu, melakukan layanan yang bebas } \\
\text { dari kesalahan, serta sikap yang baik dari pelayan. }\end{array}$ \\
$\begin{array}{l}\text { Farzaneh Mola dan } \\
\text { Jamil Jusoh (2011) }\end{array}$ & Servqual & $\begin{array}{l}\text { Menilai kepuasan terhadap layanan yang diberikan } \\
\text { dan mengetahui harapan layanan yang dinginkan } \\
\text { oleh konsumen. }\end{array}$ \\
\hline
\end{tabular}

Penelitian ini dilakukan di Hotel Kombokarno Yogyakarta. Permasalahan yang dihadapi oleh Hotel Kombokarno adalah ketidaktahuan pihak hotel mengenai kebutuhan yang diinginkan oleh konsumen. Hal ini dapat mempengaruhi kualitas layanan yang diberikan kepada konsumen yang disebabkan oleh konsumen menilai suatu aspek layanan itu penting tetapi pihak hotel tidak memenuhi aspek tersebut karena pihak hotel tidak menganggap aspek tersebut penting. Tujuan penelitian ini adalah untuk mendapatkan rancangan layanan hotel yang baik untuk memenuhi harapan layanan (service) yang diinginkan konsumen. 


\section{KAJIAN PUSTAKA}

\section{Layanan}

Menurut Yamit (2004), pelayanan adalah sekelompok manfaat yang berdayaguna baik secara eksplisit maupun implisit atas kemudahan untuk mendapatkan barang maupun jasa pelayanan. Terdapat beberapa karakteristik jasa pelayanan, yaitu:

1. Tidak dapat diraba (intangibility)

2. Tidak dapat disimpan (inability to inventory)

3. Produksi dan konsumsi secara bersamaan

4. Hambatan untuk memasuki usaha jasa lebih rendah

5. Sangat dipengaruhi oleh faktor luar (teknologi, peraturan pemerintah,dll)

\section{ServQual}

Untuk menilai kinerja layanan hotel Kombokarno, pengelola/manajer hotel perlu mempertimbangkan semua aspek yang ada untuk meningkatkan kualitas layanan (service). Salah satu metode yang digunakan untuk menilai suatu kualitas layanan adalah metode ServQual. Metode ServQual ini digunakan karena melihat suatu kualitas layanan melalui 5 dimensi, yaitu bukti langsung (tangible), Keandalan (reliability), Daya tanggap (responsiveness), Jaminan (assurance), Empathy

ServQual merupakan suatu model yang biasa digunakan untuk menilai suatu kualitas layanan. Terdapat dua faktor utama di dalam ServQual, yaitu layanan nyata yang konsumen terima (Perceived Service) dan layanan yang sesungguhnya yang diharapkan/diinginkan (Expected Service). Perceived Service dan Expected Service ini digunakan dalam konsep ServQual untuk menghitung gap yang ada. Berikut adalah persamaannya:

$$
\mathbf{G}=\mathbf{P}-\mathbf{E}
$$

Keterangan:

$\mathrm{G}=$ gap (Kesenjangan)

$\mathrm{P}=$ Perceived Service (persepsi layanan)

$\mathrm{E}=$ Expected Service (harapan layanan)

Secara konseptual kualitas layanan ServQual dapat dimodelkan dengan Gambar 1. 


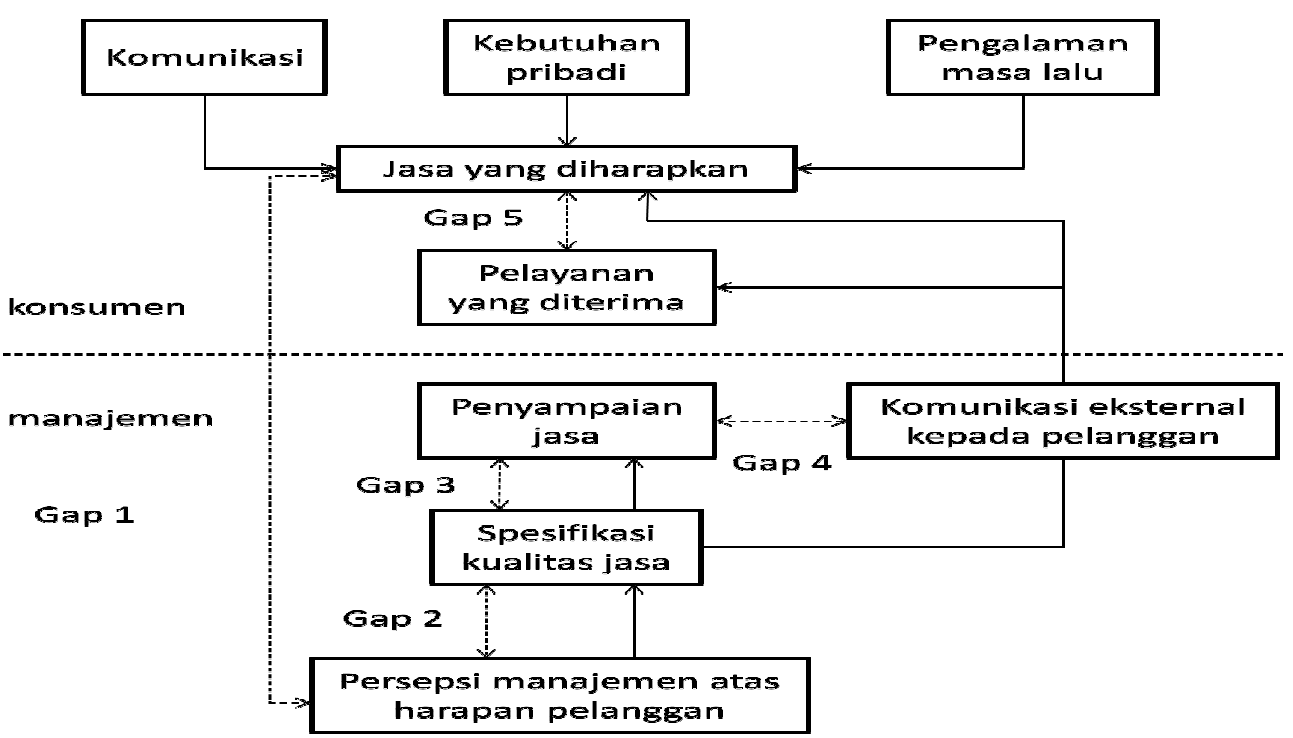

Sumber: Wijaya, 2011.

Gambar 1. Model Konseptual ServQual

Dari Gambar 1 dapat dilihat terdapat lima gap (kesenjangan) yang mengakibatkan kegagalan penyampaian jasa, yaitu (Wijaya, 2011):

Gap 1 (tidak mengetahui yang diharapkan konsumen)

Kesenjangan antara pengharapan konsumen dan persepsi manajemen.

Manajemen tidak selalu merasakan dengan tepat apa yang diinginkan pelanggan.

Gap 2 (tidak memiliki desain dan standar pelayanan yang tepat)

Kesenjangan antara persepsi manajemen dan spesifikasi kualitas jasa.

Manajemen mungkin dapat merasakan keinginan pelanggan dengan tepat, tetapi tidak menetapkan standar kinerja yang spesifik.

Gap 3 (tidak memberikan pelayanan sesuai standar pelayanan)

Kesenjangan antara spesifikasi kualitas jasa dan penyampaian jasa.

Karyawan tidak dilatih dengan baik atau mereka mengemban terlalu banyak pekerjaan dan tidak mampu atau tidak mau memenuhi standar.

Gap 4 (tidak memberikan pelayanan sesuai yang dijanjikan)

Kesenjangan antara penyampaian jasa dan komunikasi eksternal. Pengharapan konsumen dipengaruhi oleh kenyataan yang dibuat oleh perwakilan dan iklan. Hal ini juga dapat muncul karena kurangnya koordinasi antara bagian operasi dengan bagian pemasaran.

Gap 5 (perbedaan persepsi konsumen dengan harapan konsumen terhadap 
pelayanan)

Kesenjangan antara jasa yang dirasakan dan jasa yang diharapkan.

Kesenjangan ini terjadi saat konsumen mengukur kinerja perusahaan dalam cara yang berbeda dan salah menilai (misperceive) kualitas jasa.

Wijaya (2011) mengatakan, terdapat lima dimensi layanan di dalam model ServQual, yaitu:

1. Bukti langsung (tangible),

2. Keandalan (reliability),

3. Daya tanggap (responsiveness),

4. Jaminan (assurance),

5. Empathy

\section{Diagram Kartesius}

Penelitian ini menggunakan diagram Kartesius dalam kasus ini untuk membantu pengelola/manajer hotel fokus dalam meningkatkan kinerja layanan yang sesuai dengan keinginan konsumen. Pemetaan diagram kartesius bertujuan untuk mengetahui letak atribut terdapat pada kuadran berapa, sehingga dapat diketahui atribut-atribut apa saja yang harus dipertahankan, diperbaiki, dan atribut yang tidak begitu mempengaruhi kepuasan.

Diagram Kartesius merupakan metode yang dapat mengukur hubungan antara harapan/kepentingan layanan yang ingin didapatkan oleh konsumen dengan kinerja layanan yang diterima oleh konsumen. Di dalam diagram Kartesius, sumbu mendatar (X) merupakan skor tingkat kinerja dan sumbu tegak (Y) merupakan skor tingkat harapan/kepentingan. Berikut merupakan rumus untuk menghitung tingkat kinerja dan tingkat harapan:

$$
\overline{\mathrm{X}}=\frac{\sum \mathrm{X}_{\mathrm{i}}}{\mathrm{n}} \quad \overline{\mathrm{Y}}=\frac{\sum \mathrm{Y}_{\mathrm{i}}}{\mathrm{n}}
$$

Keterangan:

$X=$ Nilai rata-rata kinerja perusahaan

$\bar{X} i=$ skor kinerja perusahaan

$Y=$ Nilai rata-rata harapan/kepentingan konsumen

$Y i=$ skor harapan/kepentingan konsumen

Cara menggambar diagram Kartesius adalah dengan melakukan pembagian kuadran melalui menêtapkan titik tolak $\left(X_{N} Y_{Y}\right.$, yang dirumuskan sebagai berikut:

$$
\bar{X}=\sum_{i=1}^{N} \frac{X_{i}}{K} \quad \bar{Y}=\sum_{i=1}^{N} \frac{Y_{i}}{K}
$$

Keterangan

$\bar{X}=$ nilai rata-rata kinerja perusahaan

$Y=$ nilai rata-rata harapan/kepentingan konsumen 


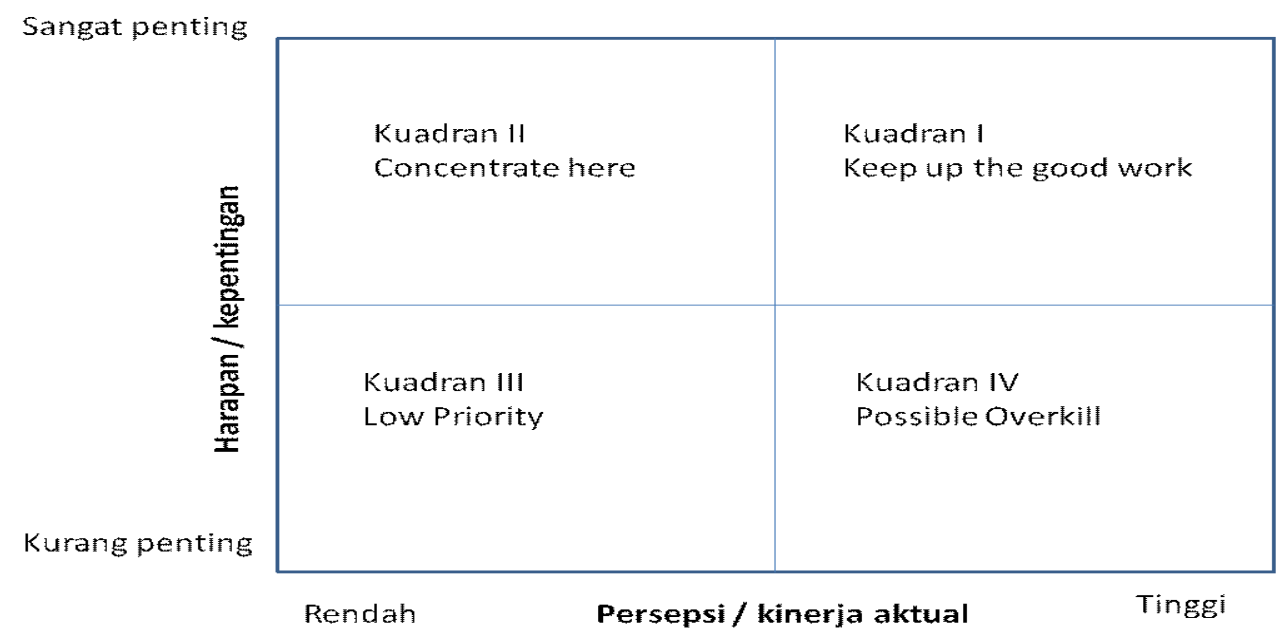

Gambar 2. Diagram Kartesius

Keterangan:

Kuadran I : Harapan/kepentingan konsumen dan kinerja perusahaan sudah tinggi. Hal ini menunjukkan bahwa kinerja perusahaan telah sesuai dengan harapan konsumen, sehingga manajemen perlu mempertahankan kualitas dari atribut-atribut yang berada di dalam kuadran I.

Kuadran II : Harapan/kepentingan konsumen yang tinggi tetapi kinerja perusahaan masih rendah. Hal ini menunjukkan bahwa manajemen perlu meningkatkan kinerja dari berbagai fakor tersebut.

Kuadran III : Harapan/kepentingan konsumen dan kinerja perusahaan rendah. Hal ini menunjukkan bahwa atribut-atribut yang di dalam kuadran ini tidak dianggap penting oleh konsumen, sehingga manajemen tidak perlu memusatkan perhatian pada atribut tersebut.

Kuadran IV: Harapan/kepentingan konsumen rendah, tetapi kinerja perusahaan tinggi. Hal ini menunjukkan bahwa atribut yang berada di kuadran ini tidak terlalu penting, sehingga manajemen dapat mengalokasikan sumber daya yang ada untuk meningkatkan kinerja aribut-atribut yang masih perlu ditingkatkan, seperti atribut-atribut yang berada di kuadran I. 


\section{METODE PENELITIAN}

Penelitian ini dilakukan pada Hotel Kombokarno. Menurut Sugiyono (2006), dalam menentukan sampel dapat menggunakan teknik nonprobability sampling dengan menggunakan accidental sampling. Teknik ini menentukan sampel secara kebetulan bertemu dengan peneliti saat penyebaran kuesioner. Penelitian ini mengambil 144 sampel tamu yang sedang menginap di hotel tersebut. Teknik pengumpulan data dengan cara kuesioner diberikan kepada tamu hotel ketika check in dan responden mengembalikan kepada resepsionis ketika check out. Untuk mendapatkan rancangan layanan hotel yang baik supaya memenuhi harapan layanan (service) yang diinginkan konsumen, maka alat analisis yang digunakan adalah menggunakan metode ServQual dan diagram Kartesius.

Variabel dalam penelitian ini adalah lima dimensi ServQual, yaitu Tangible, Reliability, Responsiveness, Assurance, Empathy. Berikut dijelaskan definisi operasional variabel penelitian yang digunakan. Tangible adalah wujud kenyataan secara fisik yang meliputi fasilitas, peralatan, pegawai, dan sarana informasi atau komunikasi. Reliability adalah kemampuan memberikan pelayanan yang dijanjikan dengan segera, akurat, dan memuaskan. Responsiveness adalah keinginan para staf untuk membantu para pelanggan dan memberikan pelayanan dengan tanggap dan peduli terhadap keluhan atau harapan pelanggan. Assurance adalah kompetensi yang sedemikian hingga memberikan rasa aman dari bahaya, resiko, atau keraguan dan kepastian yang mencakup pengetahuan, kesopanan dan sikap dapat dipercaya yang dimiliki staf. Empathy adalah sifat dan kemampuan untuk memberikan perhatian penuh kepada pelanggan, kemudahan melakukan kontak, komunikasi yang baik, dan memahami kebutuhan pelanggan secara individual.

\section{HASIL PENELITIAN}

Untuk mengetahui berkualitas atau tidaknya data yang digunakan untuk dasar analisis, dilakukannya uji validitas (kesahihan data) dan uji reliabilitas (keandalan data) di setiap indikator penelitian. Total kuesioner yang disebarkan sebanyak 144 lembar. Berdasarkan hasil uji validitas dan uji reliabilitas dengan menggunakan program SPSS, dapat dilihat bahwa semua indikator/variabel adalah valid sesuai dengan parameternya. Hal ini karena nilai Total Correlation tiap variabel lebih dari 0.159 ( $R$ Tabel Product Moment) dengan nilai taraf signifikan sebesar 5\%. Hasil uji reliabilitas setiap dimensi ServQual menunjukkan bahwa semua konsep pengukur masing-masing indikator dari kuesioner adalah reliabel. Tiap dimensi tersebut dapat dikatakan reliabel karena memberikan nilai alpha $(\alpha)>0,60$. Dimensi reliability pada harapan menunjukkan nilai alpha sebesar 0.685 dan pada kinerja sebesar 0.714 . Dimensi responsiveness pada harapan menunjukkan nilai alpha sebesar 0.714 dan pada kinerja sebesar 0.733 . Dimensi assurance pada harapan menunjukkan nilai alpha sebesar 0.709 dan 
pada kinerja sebesar 0.762 . Dimensi empathy pada harapan menunjukkan nilai alpha sebesar 0.769 dan pada kinerja sebesar 0.730. Dimensi tangibles pada harapan menunjukkan nilai alpha sebesar 0.654 dan pada kinerja sebesar 0.652 . Hal ini menunjukkan bahwa kuesioner yang digunakan merupakan kuesioner yang handal. Setelah mengetahui bahwa data yang telah dikumpul telah valid dan reliabel, maka data tersebut dapat dioleh dengan menggunakan metode ServQual dan diagram Kartesius.

\section{Pengukuran ServQual}

Analisis ServQual dilakukan dengan melihat kesenjangan (Gap) yang terjadi antara pelayanan yang diharapkan pelanggan dengan kinerja mengenai pelayanan yang diberikan oleh Hotel Kombokarno. Hasil dari metode ServQual dapat dilihat dari Tabel 2.

Tabel 2. Tabel ServQual

\begin{tabular}{|c|c|c|c|c|}
\hline No. & Atribut & Kinerja & Harapan & Gap \\
\hline \multicolumn{5}{|c|}{ Reliability (Kehandalan) } \\
\hline 1 & Kebersihan Hotel selalu terjaga & 3,782 & 4,486 & $-0,704$ \\
\hline 2 & Pemanas air berfungsi dengan baik & 3,759 & 4,386 & $-0,627$ \\
\hline 3 & Handuk yang disediakan selalu bersih & 3,642 & 4,436 & $-0,794$ \\
\hline 4 & Kasur yang nyaman & 3,851 & 4,431 & $-0,580$ \\
\hline 5 & $\begin{array}{l}\text { Perlengkapan elektronik berfungsi dengan baik } \\
\text { (lampu, AC, TV, dII) }\end{array}$ & 3,684 & 4,467 & $-0,783$ \\
\hline \multicolumn{5}{|c|}{ Responsiveness (Daya TangGap) } \\
\hline 6 & Resepsionis selalu berada di Lobby & 4,005 & 4,418 & $-0,413$ \\
\hline 7 & Call center 24 jam & 3,755 & 4,359 & $-0,604$ \\
\hline 8 & $\begin{array}{l}\text { Karyawan selalu bersedia untuk merespon keluhan } \\
\text { tamu }\end{array}$ & 3,988 & 4,441 & $-0,453$ \\
\hline 9 & $\begin{array}{l}\text { Karyawan selalu tangGap dan perduli terhadap } \\
\text { keinginan tamu }\end{array}$ & 3,848 & 4,375 & $-0,527$ \\
\hline 10 & Karyawan selalu bersedia membantu tamu & 3,832 & 4,431 & $-0,598$ \\
\hline \multicolumn{5}{|c|}{ Assurance (Jaminan) } \\
\hline 11 & Kepastian harga kamar & 3,829 & 4,395 & $-0,566$ \\
\hline 12 & Karyawan dapat dipercaya & 3,895 & 4,442 & $-0,547$ \\
\hline 13 & $\begin{array}{l}\text { Keamanan saat meninggalkan barang-barang di } \\
\text { kamar hotel }\end{array}$ & 3,969 & 4,479 & $-0,511$ \\
\hline 14 & Kenyamanan hotel selalu terjaga & 3,967 & 4,492 & $-0,526$ \\
\hline
\end{tabular}




\begin{tabular}{|c|c|c|c|c|}
\hline No. & Atribut & Kinerja & Harapan & Gap \\
\hline 15 & Fasilitas hotel aman saat digunakan & 3,988 & 4,486 & $-0,498$ \\
\hline \multicolumn{5}{|c|}{ Emphaty (Empati) } \\
\hline 16 & Karyawan selalu tersenyum & 3,950 & 4,524 & $-0,573$ \\
\hline 17 & Karyawan berlaku dan berkata sopan terhadap tamu & 3,874 & 4,514 & $-0,640$ \\
\hline 18 & $\begin{array}{l}\text { Karyawan bersifat simpatik terhadap kesusahan } \\
\text { tamu }\end{array}$ & 3,895 & 4,492 & $-0,597$ \\
\hline 19 & $\begin{array}{l}\text { Secara spontan menolong ketika melihat tamu } \\
\text { membutuhkan pertolongan (menolong tanpa } \\
\text { diminta) }\end{array}$ & 3,905 & 4,415 & $-0,509$ \\
\hline 20 & Karyawan yang komunikatif dengan tamu & 3,948 & 4,467 & $-0,518$ \\
\hline \multicolumn{5}{|c|}{ Tangible (Dimensi Bukti Fisik) } \\
\hline 21 & Bangunan hotel terlihat bagus & 3,681 & 4,457 & $-0,776$ \\
\hline 22 & Parkir memadai & 3,730 & 4,323 & $-0,592$ \\
\hline 23 & Tempat ibadah (Mushola) bersih & 3,945 & 4,438 & $-0,492$ \\
\hline 24 & Karyawan memakai seragam dengan rapi & 4,086 & 4,486 & $-0,400$ \\
\hline \multicolumn{2}{|c|}{ Rata-rata } & 3,863 & 4,443 & $-0,580$ \\
\hline
\end{tabular}

Dari Tabel 2 dapat dilihat bahwa kinerja hotel masih di bawah harapan yang diinginkan oleh konsumen. Hal ini dapat dilihat dari seluruh gap antara kinerja dan harapan bernilai negatif. Gap yang terbesar terdapat pada dimensi reliability (kehandalan) pada atribut "Handuk yang disediakan selalu bersih" sebesar $-0,794$ dan gap yang terkecil terdapat pada dimensi tangibles (dimensi bukti fisik) pada atribut "Karyawan memakai seragamnya dengan rapi" sebesar -0,400.

Manajemen akan kesulitan dan tidak fokus dalam meningkatkan kinerja hotel apabila seluruh atribut harus ditingkatkan. Agar lebih fokus dalam meningkatkan kinerja hotel, digunakanlah diagram Kartesius.

\section{Diagram Kartesius}

Diagram Kartesius dipetakan untuk mengetahui letak atribut terdapat pada kuadran berapa, sehingga dapat diketahui atribut-atribut apa saja yang harus dipertahankan, diperbaiki, dan atribut yang tidak begitu mempengaruhi kepuasan. Pengukuran tingkat kesesuaian dilakukan untuk mencari urutan prioritas perbaikan layanan. Hasil pemetaan dengan diagram Kartesius dapat dilihat pada Gambar 3. 


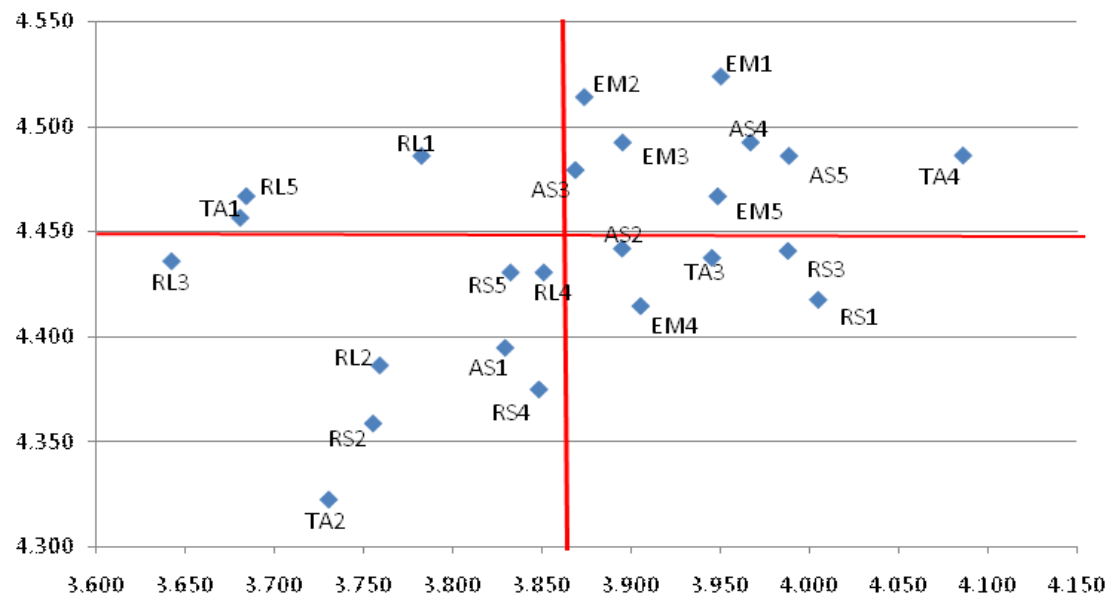

Gambar 3. Diagram Kartesius

Berdasarkan pemetaan dengan diagram Kartesius di atas, atribut-atribut pernyataan dapat dikelompokkan ke dalam kuadran masing-masing, sebagai berikut:

Kuadran I. Kuadran ini merupakan daerah yang harus dipertahankan, karena tingkat kinerja telah sesuai dengan harapan yang diinginkan oleh konsumen hotel Kombokarno. Atribut-atribut yang masuk ke dalam kuadran II adalah: Keamanan saat meninggalkan barang-barang di kamar hotel; Kenyamanan hotel selalu terjaga; Fasilitas hotel aman saat digunakan; Karyawan selalu tersenyum; Karyawan berlaku dan berkata sopan terhadap tamu; Karyawan bersifat simpatik terhadap kesusahan tamu; Karyawan yang komunikatif dengan tamu; dan Karyawan memakai seragam dengan rapi.

Kuadran II. Kuadran ini merupakan daerah yang menjadi prioritas utama yang harus dibenahi, karena atribut-atribut yang berada di kuadran ini dinilai sangat penting oleh konsumen hotel Kombokarno sedangkan tingkat kinerjanya belum memuaskan. Atribut-atribut yang masuk di dalam kuadran ini adalah: Kebersihan Hotel selalu terjaga; Perlengkapan elektronik berfungsi dengan baik (lampu, AC, TV, dII); dan Bangunan hotel terlihat bagus.

Kuadran III. Kuadran ini sering disebut sebagai daerah prioritas rendah. Hal ini dikarenakan atribut-atribut ini dinilai kurang penting bagi konsumen hotel Kombokarno dan kualitas kinerja hotel biasa-biasa saja. Hal ini bukan membuat atribut-atribut tersebut dapat dikesampingkan karena bisa saja atribut-atribut tersebut menjadi tuntutan bagi perusahaan dalam menjalankan kinerjanya. Atribut-atribut yang 
masuk ke dalam kuadran III adalah: Pemanas air berfungsi dengan baik; Handuk yang disediakan selalu bersih; Kasur yang nyaman Call center 24 jam; Karyawan selalu tanggap dan perduli terhadap keinginan tamu; Karyawan selalu bersedia membantu tamu; Kepastian harga kamar; dan Parkir yang memadai.

Kuadran IV. Kuadran ini sering disebut sebagai daerah yang berlebihan dalam pelaksanaannya. Hal ini dikarenakan konsumen hotel Kombokarno menganggap atribut-atribut tersebut tidak terlalu penting, tetapi kinerja hotel dilakukan dengan sangat baik. Atribut-atribut yang berada di kuadran IV ini adalah: Resepsionis selalu berada di Lobby; Karyawan selalu bersedia untuk merespon keluhan tamu; Karyawan yang dapat dipercaya; Secara spontan menolong ketika melihat tamu membutuhkan pertolongan (menolong tanpa diminta); dan Tempat ibadah (Mushola) yang bersih.

\section{PEMBAHASAN}

Hasil analisis menunjukkan adanya kesenjangan (gap) yang terjadi antara pelayanan yang diharapkan konsumen dan penilaian konsumen mengenai pelayanan yang diberikan oleh Hotel Kombokarno bernilai negatif (-). Ini berarti bahwa seluruh jasa yang dipersepsikan tidak sesuai dengan jasa yang diharapkan. Jika gap mendekati nol, makin sedikit kesenjangan yang terjadi dan jika kinerja yang dilakukan perusahaan sesuai dengan kriteria yang diharapkan konsumen, instansi mendapatkan citra dan dampak positif.

Dalam dimensi reliability (kehandalan), atribut Handuk yang disediakan selalu bersih memiliki gap tertinggi yaitu sebesar $-0,794$. Selanjutnya disusul atribut Perlengkapan elektronik berfungsi dengan baik (lampu, AC, TV, dII) memiliki gap sebesar $-0,783$. Hal ini menunjukkan bahwa pengelola hotel Kombokarno perlu lebih teliti dalam membersihkan handuk untuk konsumen. Pengelola hotel perlu mengecek ulang semua handuk yang ada sebelum diserahkan kepada konsumen. Selain itu, pengelola hotel perlu mengecek setiap peralatan elektronik di setiap kamar ketika konsumen meninggalkan kamar. Hal ini dilakukan agar diketahui apakah karyawan masih bekerja dengan baik atau tidak, sehingga dapat diperbaiki secepatnya apabila ditemui peralatan elektronik yang telah rusak.

Pada dimensi responsivenes (daya tanggap), atribut Call center 24 jam memiliki gap tertinggi yaitu sebesar $-0,604$, sedangkan atribut Karyawan selalu bersedia membantu tamu memiliki gap tertinggi kedua yaitu sebesar $-0,598$. Hal ini menunjukkan bahwa konsumen ingin karyawan yang berada di resepsionis selalu siap untuk menjawab panggilan konsumen melalui telepon yang ada. Selain itu, konsumen juga menginginkan karyawan selalu membantu tamu yang meminta pertolongan dengan senang hati. 
Pada dimensi assurance (jaminan), atribut Kepastian harga kamar memiliki gap terbesar yaitu sebesar $-0,566$. Hal ini menunjukkan bahwa konsumen tidak mendapatkan kepastian harga kamar ketika ingin mem-booking kamar, sebaiknya pengelola hotel Kombokarno telah menetapkan harga kamar yang telah fix dan tidak berubah-ubah setiap harinya.

Pada dimensi emphaty (empati), atribut Karyawan berlaku dan berkata sopan terhadap tamu memiliki gap tertinggi yaitu sebesar $-0,640$. Hal ini menunjukkan bahwa karyawan masih sering berbicara tidak sopan kepada konsumen. Sebaiknya pengelola/manajer hotel selalu memperingatkan kepada para karyawan yang bekerja di hotel Kombokarno untuk selalu berbicara dan berlaku sopan kepada para tamu yang ada.

Pada dimensi tangibles (dimensi bukti fisik), atribut Bangunan hotel terlihat bagus memiliki gap tertinggi, yaitu sebesar $-0,776$. Hal ini menunjukkan bahwa konsumen menilai bangunan hotel sudah tidak terlihat bagus lagi. Sebaiknya pengelola/manajer hotel sudah mulai membahas untuk melakukan renovasi bagunan hotel. Hal ini dilakukan agar bangunan hotel tidak terlihat kuno.

Dengan melihat gap dari metode ServQual di atas, sebaiknya pengelola/ manajer hotel perlu meningkatkan semua atribut yang ada. Atribut-atribut tersebut perlu diperbaiki karena seluruh gap dari metode ServQual menunjukkan hasil negatif. Namun, pengelola/manajer hotel tidak dapat fokus dalam memperbaiki kinerja layanan apabila seluruh atribut ingin diperbaiki, maka digunakan diagram Kartesius untuk memetakan atribut-atribut kualitas jasa pelayanan yang telah dianalisis.

Hasil diagram Kartesius menunjukkan bahwa atribut Kebersihan Hotel selalu terjaga; Perlengkapan elektronik berfungsi dengan baik (lampu, AC, TV, dll); dan Bangunan hotel terlihat bagus menjadi prioritas utama dalam perbaikan kualitas kinerja layanan hotel. Atribut-atibut tersebut harus menjadi prioritas utama dalam perbaikan karena atribut-atribut tersebut masuk ke dalam kuadran I. Hal ini menunjukkan bahwa harapan konsumen mengenai atribut-atribut tersebut melebihi rata-rata yang ada, sedangkan kinerja yang diberikan lebih rendah dari rata-rata yang ada.

\section{PENUTUP}

Berdasarkan hasil penelitian dan kajian yang telah diuraikan sebelumnya, maka dapat diambil simpulan bahwa layanan (kinerja) yang diberikan oleh pihak hotel Kombokarno masih belum memenuhi harapan layanan yang diinginkan oleh konsumen. Hal ini dapat dilihat dari nilai gap pada metode ServQual yang secara keseluruhan masih bernilai negatif. Atribut kebersihan hotel selalu terjaga (RL1); perlengkapan elektronik berfungsi dengan baik (lampu, AC, TV, dII) (RL5); dan bangunan hotel terlihat bagus (TA1) merupakan perioritas utama yang harus dibenahi. Hal ini dilihat dari hasil pemetaan diagram Kartesius. Ketiga atribut 
tersebut masuk ke dalam kuadran I yang menunjukkan bahwa konsumen memiliki harapan yang tinggi terhadap atribut tersebut sedangkan kinerja yang diberikan kepada konsumen masih rendah.

Berdasarkan hasil dan simpulan penelitian yang telah dijabarkan, maka berikut saran-saran yang dapat diberikan, yaitu menyediakan peralatan dan perlengkapan kebersihan yang memadai. Selain itu pengelola juga perlu melakukan training housekeeper. Hal ini dilakukan agar pekerja kebersihan memiliki keahlian yang cukup dalam membersihkan seluruh hotel. Pengecekan dan perawatan perlengkapan elektronik secara berkala perlu dilakukan agar peralatan elektronik seperti lampu, AC, TV, dll dapat bekerja dengan baik dan lebih terawat. Perbaikan yang perlu dilakukan oleh pengelola/manajer hotel untuk bangunan hotel terlihat bagus adalah melakukan peremajaan gedung secara berkala. Hal ini dilakukan agar bangunan hotel tidak terlihat kuno. Perlengkapan hotel seperti sofa dan meja di lobi secara berkala perlu diganti agar tidak terlihat kuno dan usang. Disarankan untuk pihak pengelola/manajer hotel agar secara rutin melakukan evaluasi kinerja layanan hotel.

Akibat dari keterbatasan peneliti dalam meneliti, maka ada beberapa hal yang perlu pengembangan lebih lanjut, antara lain: penelitian perlu dikembangkan dengan menilai pula kinerja restoran hotel; perlu dikembangkan SOP dan instruksi kerja atribut lainnya; dan penelitian perlu dikembangkan dengan melihat lebih mendalam mengenai beban kerja pekerja setiap atribut, sehingga mendapatkan jumlah pasti pekerja yang diperlukan disetiap atribut.

\section{DAFTAR PUSTAKA}

Gržinić, J, 2007, Concepts Of Service Quality Measurement In Hotel Industry, Professional Paper, Vol. 16, hal 81-98.

İkiz \& Masoudi 2008, A QFD and ServQual Approach to Hotel Service Design, http://web.deu.edu.tr/isletme/ifddergi/web files/911731.pdf diakses 18 Maret 2011.

Markovi 'c \& Raspor 2010, Measuring Perceived Service Quality Using servqual: A Case Study of the Croatian Hotel Industry, Journal of Management, Vol.5, No. 3, halaman 195-209.

Mola \& Jusoh 2011, Service Quality in Penang Hotels: A gap Score Analysis, World Applied Sciences Journal, Vol. 12, hal. 19-24.

Parasuraman, et.al, 1985. A Conceptual Model Of Service Quality and it's Implications For Future Research. Journal of Marketing, Vol.49, No.3, hal. 41-50. 
Tan \& Pawitra 2001, Integrating Servqual and Kano's model into QFD for Service excellence development, Journal of Managing Service Quality, vol. 11 , No. 6 , hal. $418-430$.

Wijaya,Tony 2011, Manajemen Kualitas Jasa, Jakarta: PT Indeks.

Yamit, Zulian 2004, Manajemen Kualitas: Produk \& Jasa, Edisi pertama, Yogyakarta: Ekonisia. 